\title{
Optimal Limited-stop Bus Routes Selection Using a Genetic Algorithm and Smart Card Data
}

\author{
Yongju Yi, Ph.D., and Keechoo Choi, Ph.D., Ajou University \\ Young-Jae Lee, Ph.D., Morgan State University
}

\begin{abstract}
In recent years, express bus service has come into the spotlight by overcoming slow bus operating speeds while maintaining its accessibility when it operates with local bus services. This study developed an optimal limited-stop bus routes selection (LSBRS) guideline as a scenario-based analysis and compared it with case study results. Smart card data and a genetic algorithm (GA) were used to develop the model with different scenarios. Then, total travel time savings as a result of implementing limited-stop bus service generated by the GA model were computed. The effectiveness of each factor was verified by multiple regression analysis, and the LSBRS methodology was determined. This methodology was applied to Suwon, Korea, as a case study. As a result, travel time savings were estimated to be $9.0-19.0 \%$. The ranking of the total travel time savings proposed by the LSBRS methodology presented a similar tendency with that of the casestudy analysis.
\end{abstract}

Key words: Limited-stop bus, genetic algorithm, smart card data, multiple regression analysis, public transportation, case study

\section{Introduction}

Because of its flexibility of route operation and excellent accessibility, bus is a major transit mode for mid- or short-distance trips in most cities. In Seoul, the capital of South Korea, with a population of 10 million, the modal share of bus transit is $27.4 \%$ (as of 2012) (City of Seoul 2014), in spite of the existing dense subway network. In Suwon, a suburban city outside of Seoul with a population of 1.2 million, the modal share of bus transit is 34.8\% (as of 2011) (Metropolitan Transit Authority of Korea 2013) in an area with an insufficient number of subway lines. 
In recent years, however, the modal share of bus transit in Korea has been stagnant or slightly decreasing because of several factors, such as an increase in passenger car ownership and the expansion of road and subway networks. To improve the competitiveness of public transit, two key factors, accessibility and mobility, should be assured to a certain level. These two concepts generally conflict with one another because when more bus stops are added to increase accessibility, operating speed is lowered. To satisfy these two conflicting concepts, the subway network was devoted to increasing mobility, whereas most bus transit was operated for greater accessibility. Therefore, in terms of travel time, bus transit has a limitation in terms of mobility compared to that of other modes, such as passenger car or subway. Figure 1 shows the average system speeds of a wide range of modes. As shown, the average speeds of bus systems are roughly half of that of rail systems, reinforcing the idea that bus systems are relatively less competitive as a transit mode for mid-or long-distance travels.

FIGURE 1.

Average transit system speeds by mode

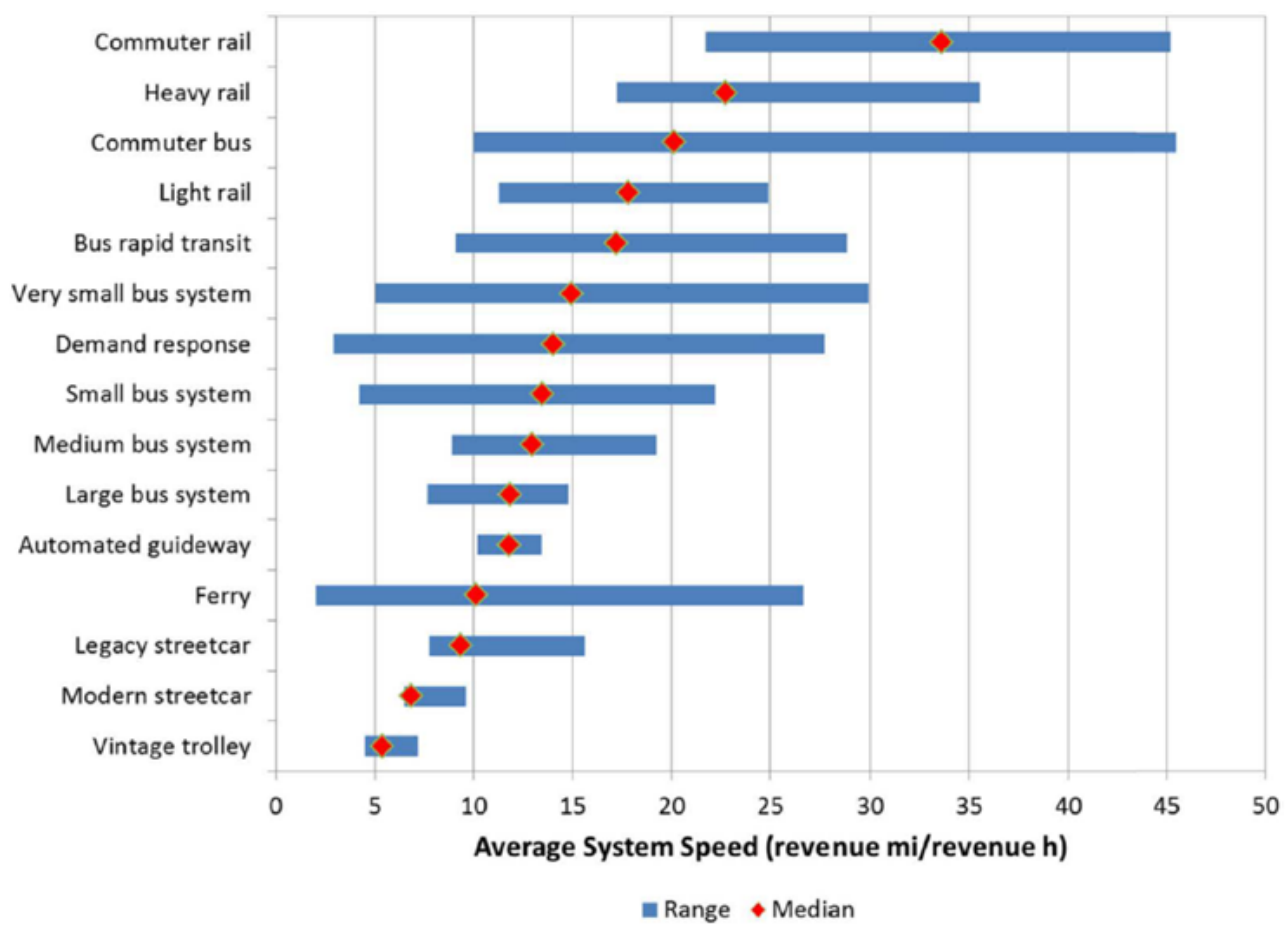

Source: Ryus et al. 2013

Some rail lines in the Seoul metropolitan area and bus lines in several large cities have introduced express services while maintaining local services to satisfy both accessibility and mobility needs; however, there exists a need for a systematic approach to decide the optimal routes and stops for the express services. This study provides optimal limited-stop bus routes selection (LSBRS) methodology. As a flexible and economic mode of transit to introduce express service, limited-stop bus service could provide social benefits such as saving user travel time and operation costs as well as increase the number of passengers due to its more competitive service. 
To develop the model, this study used smart card data and a genetic algorithm (GA). Smart card data, which are widely used in Korea, provide a set of complete trip data. Because the public transit fare of the Seoul metropolitan area is based on travel distances, users tag smart cards when boarding and alighting. As a result, the origindestination (OD) location and time of each passenger can be obtained. Smart card data are widely used in the transit research area, especially in modal and route choice estimation models (e.g., Morency et al. 2007; Kurauchi et al. 2014; Jánošíková et al. 2014), OD estimation (e.g., Wang 2010; Jun and Dongyuan 2013; Nassir et al. 2011), or travel behavior analysis (e.g., Agard et al. 2006; Tao et al. 2014; Nishiuchi et al. 2013).

GA is used to solve non-linear programming problems, particularly in the transit network field. Kalantari et al. (2014) proposed a GA model considering geographic and operational similarity to solve a bus network modification problem. Nayeem et al. (2014) developed a GA model to maximize the number of satisfied passengers, minimize total travel time, and maximize the total number of passengers to solve a transit network design problem. Zargari et al. (2013) considers the location of depots in designing a bus network with a GA model to minimize deadhead travel time (travel time when a vehicle operates without regular services, such as when coming from a garage), empty seats, OD pairs that require more than two transfers, and user and operator costs. Additional studies using GA have been conducted in transit network design (e.g., Amiripour et al. 2015; Kuan et al. 2006; Fan and Machemehl 2004; Fan and Machemehl 2006) and in operational aspects such as optimizing frequency or minimizing transfer time (e.g., Cevallos and Zhao 2006; Ngamchai and Lovell 2003; Lee et al. 2014).

Although most of the existing research related to express transit services deals with restructuring the whole network or improving a single route, most cities have very well-organized transit route networks through spontaneous development or practical policies to satisfy user needs and operator efficiency. Therefore, instead of restructuring the whole transit network, this study provides the methodology to select an optimal route set from the currently-operating transit network that is maximizing system efficiency without large-scale restructuring of the whole network.

Figure 2 presents the process of this study. First, the general LSBRS methodology was developed to find the relationship between total travel time saved and various combinations of factors that influence total travel time savings. Because influencing factors from actual OD data would be biased to certain conditions, scenario ODs were created with the factors that influence the effectiveness of limited-stop bus implementation and used at this step. As a second step, the methodology was applied to the case of Suwon and compared with the LSBRS criteria for the total travel time saved. 
FIGURE 2.

Process of optimal limitedStep 1: Develop the General Methodology

stop bus routes selection

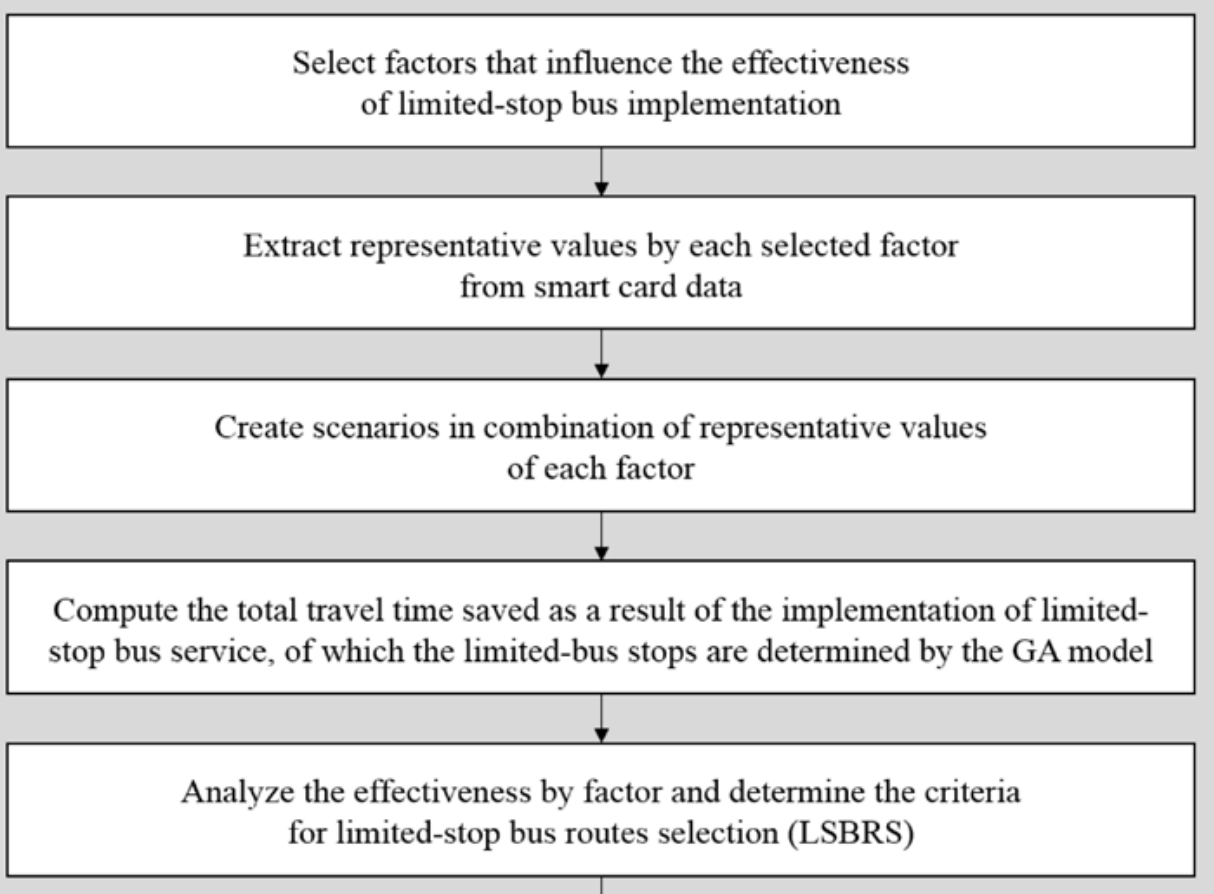

\section{Step 2: Methodology Verification}

Compute the total travel time saved as a result of the implementation of limitedstop bus service: in case of Suwon city (73 routes)

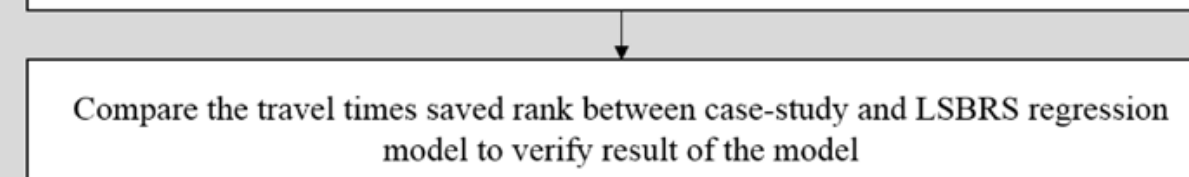

\section{Methodology}

\section{Smart Card Data}

After the implementation of distance-based integrated transit fare for the Seoul metropolitan area in 2007, smart card usage increased greatly - up to $98 \%$-because of the implemented discount on transfer trips. In Korea, all data include temporal and spatial references for all transit modes used in one trip; these data can be gathered due to the tagging smart card when both boarding and alighting. The contents of smart card data include:

- User class (Regular, Student, Senior, Disabled ...)

- Mode codes* (bus, rail ...) 
- Route ID* and vehicle ID

- Total distance $(\mathrm{m})$

- Total in-vehicle time and total time (min)

- Boarding and alighting time*

- Boarding and alighting stop ID*

- Total cost

${ }^{*}$ Recording $7^{\text {st }}-5$ th mode of transit used; transfer discount offered up to 4 times

In this study, actual route and trip data from smart card data were used to extract representative values of each factor that influences the effectiveness of the limitedstop bus implementation. Trip data from the whole day of Wednesday, October 16, 2013, (663,616 passengers who boarded or alighted in Suwon city) were used to obtain average weekday trip patterns. Stop-based ODs by each route were created by each passenger's boarding/alighting time and stop information.

\section{Selection of Influencing Factors for Limited-Stop Bus Service}

To verify the factors that influence the limited-stop bus service, Schwarcz (2004) analyzed several factors such as resources, frequency share between regular service and express service, limited stops, headway distribution, distance between stops, OD demand, local and limited running time, and travel time component weights as key inputs of the model. The results showed that high concentrations of OD and long passenger trips are both critical and, additionally, that existing headway and ridership and the potential for route level running time savings influence the corridor potential for limited-stop bus service. Leiva (2010) developed limited-stop service design models that can accommodate the operating characteristics of a bus corridor, given an OD trip matrix and a set of services that are $a$ priori attractive. The demand variability among different OD pairs and the average trip length strongly influence benefits. The model developed by Tétreault et al. (2010) shows that major activity points and stop spacing are key factors to operate a limited-stop service with high efficiency.

In reference to the aforementioned literature, this study selected route length, stop spacing, average trip length, and the OD pattern as the factors influencing a limitedstop bus service.

Representative values of each factor, with the exception of the OD pattern, were assumed in three cases: values of the $15^{\text {th }}, 50^{\text {th }}$, and $85^{\text {th }}$ percentiles. Table 1 shows the values extracted from route and trip data of 73 regular bus routes that operate in Suwon with smart card data. Meanwhile, representative values of the OD pattern were assumed as (1) flat: all OD pairs have similar passenger levels, (2) two peaks: two stops have highly concentrated boarding/alighting passenger levels, and (3) four peaks: four stops have highly concentrated boarding/alighting passenger levels. In total, $81\left(=3^{4}\right)$ scenarios were used with four factors and three representative values. 
TABLE 1.

Representative Values of Limited-stop Bus Service Affecting Factors

\begin{tabular}{|l|c|c|c|c|}
\hline & Route Length & Stop Spacing & Average Trip Length & OD Pattern* \\
\hline 15th percentile value & $19.7 \mathrm{~km}$ & $390 \mathrm{~m}$ & $2.8 \mathrm{~km}$ & Flat \\
\hline 50th percentile value & $32.5 \mathrm{~km}$ & $430 \mathrm{~m}$ & $3.4 \mathrm{~km}$ & Two peaks \\
\hline 85th percentile value & $42.4 \mathrm{~km}$ & $470 \mathrm{~m}$ & $4.1 \mathrm{~km}$ & Four peaks \\
\hline
\end{tabular}

*OD pattern: Irrelevant to percentile values

\section{Model Definitions}

The effectiveness of the limited-stop bus is defined by the amount of passenger total travel time savings. Therefore, the objective function of this model was to minimize passenger total travel time using route $k\left(Z_{k}\right)$, which is defined as the following:

$$
\min Z_{k}=\sum_{r=1}^{N-1} \sum_{s=r+1}^{N}\left(q_{r s} \cdot T T_{r s}\left(i_{n}, h_{L}, h_{R}\right)\right)
$$

Subject to:

$$
\begin{aligned}
& V_{L}+V_{R}=V_{T} \\
& V_{L}>0, V_{R}>0 \\
& i_{n}=[0,1], \forall i_{n} \in S_{k}
\end{aligned}
$$

Where $h_{L}=\frac{60}{V_{L}}, h_{R}=\frac{60}{V_{R}}$

$N$ is the total number of stops of route $k, r$ and $s$ are boarding and alighting stops, respectively, and $q_{r s}$ is the number of passengers who board at stop $r$ and alight at stop $s$. Total travel time for a passenger who boards at stop $r$ and alights at stop $s, T T_{r s}$, is affected by stops of limited-stop bus route $\left(i_{n}\right)$, headway of local bus service $\left(h_{L}\right)$ and rapid bus service $\left(h_{r}\right)$. $S_{k}$ means total stops set of route $k$. Total vehicle fleet per hour $\left(V_{T}\right)$ consists of local service vehicle fleet per hour $\left(V_{L}\right)$ and rapid service vehicle fleet per hour $\left(V_{R}\right)$, and is the same as the existing service scheme which is operated as local-only service. Stops of limited-stop bus route $\left(i_{n}\right)$ are selected by the GA model which minimizes total travel time. If a limited-stop bus stops at $n^{\text {th }}$ stop, $i_{n}$ is set as 1 , otherwise $i_{n}$ is set as 0 . Passenger travel time consists of in-vehicle travel time, waiting time and transfer time. Access time is not considered because passengers do not change their origin or destination stops against current situations, which results in an unchangeable value regardless of limited-stop bus service.

To maintain consistent levels for each scenario, the total OD amount (the sum of each OD trip) is calculated by the average number of passengers per route-km of Suwon (174 passengers $/ \mathrm{km}$ ) multiplied by route length. Running time savings by skipping a stop consists of boarding and alighting time saving, acceleration and deceleration time saving, and intersection signal delay saving. Figure 3 shows the total travel time estimation model algorithm. Stops of the limited-stop bus route $\left(i_{n}\right)$ are adjusted at each 
generation until total travel time is minimized. At the point at which total travel time is minimized, the travel time estimation model algorithm has finished selecting the set of limited-stop bus stops.

FIGURE 3.

Total travel time estimation model algorithm

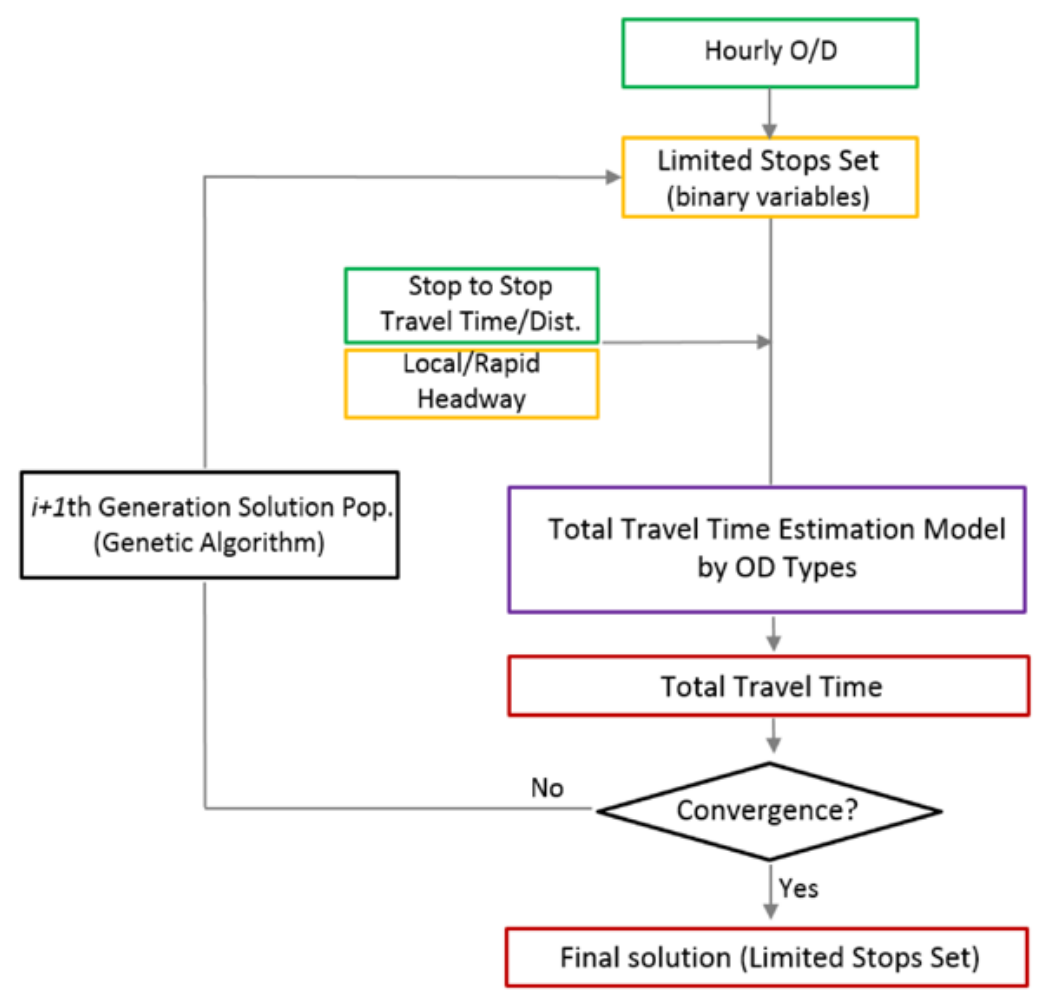

\section{Model Assumptions}

OD types were classified into three categories (shown in Figure 4): (1) between localonly stops (LL), (2) local-only stop to limited-stop bus stop, or limited-stop bus stop to local-only stop (LE/EL), (3) between limited-stop bus stops (E-E), "LL" in (1) and "LE/EL" in (2) should be "L-L" and "L-E/E-L" just like "E-E" in (3).

FIGURE 4. Examples of OD types

In the case of $L-L$ and $L-E / E-L$, total travel time by local bus and total travel time by local bus and limited-stop bus with transfer were compared to assign a passenger route to that of the one with shorter travel time. Running speed was assumed as $20 \mathrm{~km} / \mathrm{h}$, an average of regular bus routes in Suwon. In total, $50 \%$ of the total fleet was assigned 
to the limited-stop bus service to minimize the waiting time for both bus services. Passengers who use the local-only stop do not change their initial boarding stop and final alighting stop even though a neighboring stop operates limited-stop bus service and ensures shorter travel time. This assumption was required to ease the complexity of the model that is repetitively applied to a number of routes and would be considered after the selection of limited-stop bus routes for detailed decisions about limited-stop bus route stops.

\section{OD Creating Method (for Scenario-based Analysis)}

In the case of scenario-based analysis, the assumption of OD form is one of the most critical points. First, traffic was generated for each stop by the OD pattern. In the case of flat type, the average traffic amount of each stop (referred to as Trips $s_{k}$ for kth stop) is the total OD amount (Tot) divided by the total number of boardable stops (StopNo-1; deduct last stop from the number of total stops). By normal distribution with Trips $_{k}$ as the average, the following process generates random traffic volume with the number of stops and is applied to variation.

$$
\text { Trips } \left._{k} \sim N(\text { Tot/StopNo-1,(StopNo })^{2}\right)
$$

where $\forall k \geq 1$ and $k \leq($ StopNo-1)

Divide by average stop spacing distance; average trip distance is substituted to average number of traveled stops (Trip). By normal distribution with Trip as average, the following process generates the number of random travel stops $\left(\operatorname{TripTo}_{j}{ }^{k}\right.$ ) for each passenger (as the amount of $j$ ) who boards at $k$ th stop. The variation is proportional to the number of remaining stops to reflect trip distance diversity.

$$
\operatorname{TripTo}_{j}^{k} \sim N\left(\text { Trip },(\text { Trip } / k)^{2}\right)
$$

where $\forall k \geq 1$ and $k \leq($ StopNo-1)

$$
\forall j \geq 1 \text { and } j \leq \text { Tripsk }
$$

In the case of two or four peaks types, a certain portion of total OD amount is reserved to be assigned for each type; $30 \%$ for two peaks and $40 \%$ for four peaks. First, the same method used to create the OD pattern of flat type is applied to the rest of the OD amount. The amount of the reserved portion is additionally applied. For two peaks type, $15 \%$ of total OD amount is boarding at the first peak stop and $15 \%$ of total OD amount is alighting at the second peak stop. For four peaks type, 10\% of total OD amount is boarding at the first peak stop, $10 \%$ of total OD amount is boarding and alighting at the second and third stop each, and 10\% of total OD amount is alighting at the fourth peak stop. Locations of peak stops are determined with equal partition; $33^{\text {rd }}$ percentile and $67^{\text {th }}$ percentile ordered stops are designated as peak stops for two peaks type, and $20^{\text {th }}$, $40^{\text {th }}, 60^{\text {th }}, 80^{\text {th }}$ percentile ordered stops are designated as peak stops for four peaks type. The distribution of peak stops is identically applied as Equation 3. 


\section{Travel Time Estimation}

In this study, modification of the limited-stop bus routes was not taken into account although there are shortcut paths between limited-stop bus stops without stopping at the local-only stop(s). In other words, line alignments of both local bus routes and limited-stop bus routes were assumed as the same. The calculation of the rapid bus travel time between the $r$ stop and $s$ stop $\left(t_{r s}\right)$ was dependent on whether the limitedstop bus stops at the $n^{\text {th }}$ stop. In-vehicle local bus travel time, $t_{r s}^{L}$ and in-vehicle rapid bus travel time, $t_{r s}^{R}$, were calculated according to the following:

$$
\begin{aligned}
t_{r s}^{L} & =\sum_{n=r}^{s-1} t_{n, n+1} \\
t_{r s}^{R} & =\sum_{n=r}^{s-1} t_{n, n+1}-\sum_{n=r}^{s-1} t_{n, n+1}^{r e d u c e d} \cdot\left(1-i_{n}\right)
\end{aligned}
$$

Where:

$$
\begin{aligned}
& t_{n, n+1}=\text { bus travel time from } n^{\text {th }} \text { stop to } n+1^{\text {th }} \text { stop } \\
& t_{n, n+1}^{\text {reduced }}=\text { reduced travel time when bus passes the } n^{\text {th }} \text { stop, calculated as } \\
& \text { AccDcc + } \text { OnOffTime }_{n}+\text { Signal }_{n}
\end{aligned}
$$

$A c c D c c=$ time lost while decelerating from and accelerating to cruise speed for passengers boarding or alighting at stops (11.6 sec. [Robinson 2013])

OnOffTime $_{n}=$ boarding and alighting time at $n^{\text {th }}$ stop $(2.3 \mathrm{sec} /$ passenger for boarding and $2.0 \mathrm{sec} /$ passenger for alighting (from smart card data), applying larger value between total boarding time and total alighting time)

$$
\text { Signal }_{n}=\text { expected signal delay reducing time by skipping } n^{\text {th }} \text { stop }
$$

Expected signal delay reducing time (Signal ${ }_{n}$ ) reflects earlier arriving at the intersection when the limited-stop bus skips a local-only stop prior to the intersection, which allows for the increasing probability of passing through the intersection without stopping because of a red signal phase. In general, the signal coordination is aimed for regular private vehicles, which do not stop at bus stops. That means a bus which stops at a bus stop is more likely to miss the signal progression at the next signal because of the additional time consumption at the bus stop and increased travel time to the next intersection. If a bus does not need to stop at the bus stop and can skip the bus stop, most likely the bus can have a higher chance to enjoy the signal coordination just like the regular private vehicles. "Von Stain's law of transit stop locations," which refers to the bus stop location placement strategy with consideration for coordinated signals 
to minimize the effects caused by signal delays, introduced the similar idea (Vuchic 2007). Using the average values of operating attributes of Suwon, with 161 seconds for average cycle time and $42 \%$ for $\mathrm{g} / \mathrm{C}$ (green time/Cycle time), the probability that a vehicle receives a green signal when arriving at the intersection is 68 seconds ( $42 \%$ of 161), and that of receiving a red signal is 93 seconds ( $58 \%$ of 161 ). In this situation, expected average signal delay time is 27 seconds $\left(\sum_{i=1}^{93} i / 161\right)$. If the bus arrives earlier at the intersection as much as $X$ seconds because of boarding and alighting time and acceleration and deceleration time savings, expected average signal delay time is reduced as much as $\sum_{i=X}^{93} i / 161$.

Total travel time calculation is applied distinctly by three OD categories: L-L, L-E/E-L, and E-E. Total travel time is calculated by multiplying travel time and travel demand for every OD pair. In the case of $L-L$ or $L-E / E-L$, total travel time is compared when using a local bus only and when using a local bus and limited-stop bus with transfer. After the comparison, all travel demand of OD pairs is assigned to one that takes less travel time:

$$
\begin{array}{ll}
T T_{r s}^{L L}=\min \left(V T T_{r s}^{L}, V T T_{r s}^{L+E+L}\right) & \text { (OD Type 1: L-L) } \\
T T_{r s}^{L E}=\min \left(V T T_{r s}^{L}, V T T_{r s}^{L+E}\right) & \text { (OD Type 2: L-E) } \\
T T_{r s}^{E L}=\min \left(V T T_{r s}^{L}, V T T_{r s}^{E+L}\right) & \text { (OD Type 3: E-L) } \\
T T_{r s}^{E E}=V T T_{r s}^{E} & \text { (OD Type 4: E-E) }
\end{array}
$$

Where:

$$
\begin{aligned}
& V T T_{r s}^{L}=W_{\text {wait }} \times T_{\text {Lwait }}+t_{r s}^{L}+\sum_{n=r}^{s-1} \text { OnOffTime }_{n} \\
& V T T_{r s}^{E}=W_{\text {wait }} \times T_{\text {Ewait }}+t_{r s}^{R}+\sum_{n=r}^{s-1} \text { OnOffTime }_{n} \cdot\left(1-i_{n}\right) \\
& V T T_{r s}^{L+E}=W_{\text {wait }} \times T_{\text {Lwait }}+W_{\text {trf }} \times T_{\text {Ewait }}+t_{r a}^{L}+t_{a s}^{R}+\sum_{n=r}^{a-1} \text { OnOffTime }_{n} \\
& +\sum_{n=a}^{s-1} \text { OnOffTime }_{n} \cdot\left(1-i_{n}\right) \\
& V T T_{r s}^{E+L}=W_{\text {wait }} \times T_{\text {Ewait }}+W_{\text {trf }} \times T_{\text {Lwait }}+t_{r a}^{R}+t_{a s}^{S}+\sum_{n=r}^{a-1} \text { OnOffTime }_{n} \cdot\left(1-i_{n}\right) \\
& +\sum_{n=a}^{s-1} \text { OnOffTime }_{n} \\
& V T T_{r s}^{L+E+L}=W_{\text {wait }} \times T_{\text {Lwait }}+W_{\text {trr }} \times\left(T_{\text {Lwait }}+T_{\text {Ewait }}\right)+t_{r a}^{L}+t_{a b}^{R}+t_{b s}^{L} \\
& +\sum_{n=r}^{a-1} \text { OnOffTime }_{n}+\sum_{n=a}^{b-1} \text { OnOffTime }_{n} \cdot\left(1-i_{n}\right)^{+} \sum_{n=b}^{s-1} \text { OnOffTime }_{n}
\end{aligned}
$$


$T_{\text {Lwait }}=$ Local bus average waiting time (1/2 of headway)

$T_{\text {Ewait }}=$ Limited-stop (express) bus average waiting time (1/2 of headway)

$W_{\text {wait }}=$ waiting time weight

$W_{\text {trf }}=$ transfer time weight

$t_{r s}^{L}=$ in-vehicle local bus travel time

$t_{r s}^{R}=$ in-vehicle rapid bus travel time

OnOffTime $_{n}=$ boarding and alighting time at $n^{\text {th }}$ stop

Although research such as Fan and Machemehl (2009) considered passenger arrival model, average waiting time in this study is assumed as half of headway because maximum headway is set as 20 minutes without schedule information, which is a common condition for regular urban bus service in Korea. Weight for waiting and transfer time is referenced from Son et al. (2007), 1.83 times and 1.37 times of in-vehicle time, respectively. The total travel time calculation process is shown in Figure 5 . If the limitedbus service stops at both origin and destination bus stops (E-E), in-vehicle time is reduced by skipping local-only stops. When the limited-bus service stops at only one of the origin or destination bus stops (L-E/E-L), there are two options: using both local and limited-stop buses with transfer in consideration of additional waiting time and reduced in-vehicle time, or using only the local bus to the destination if total travel time (TT) is shorter than using both local and limited-stop buses with transfer. If the limited-bus service does not stop at both origin and destination bus stops (L-L), travel time of using a limited-stop bus with two transfers and travel time of using only a local bus are compared.

FIGURE 5.

Total travel time calculation process

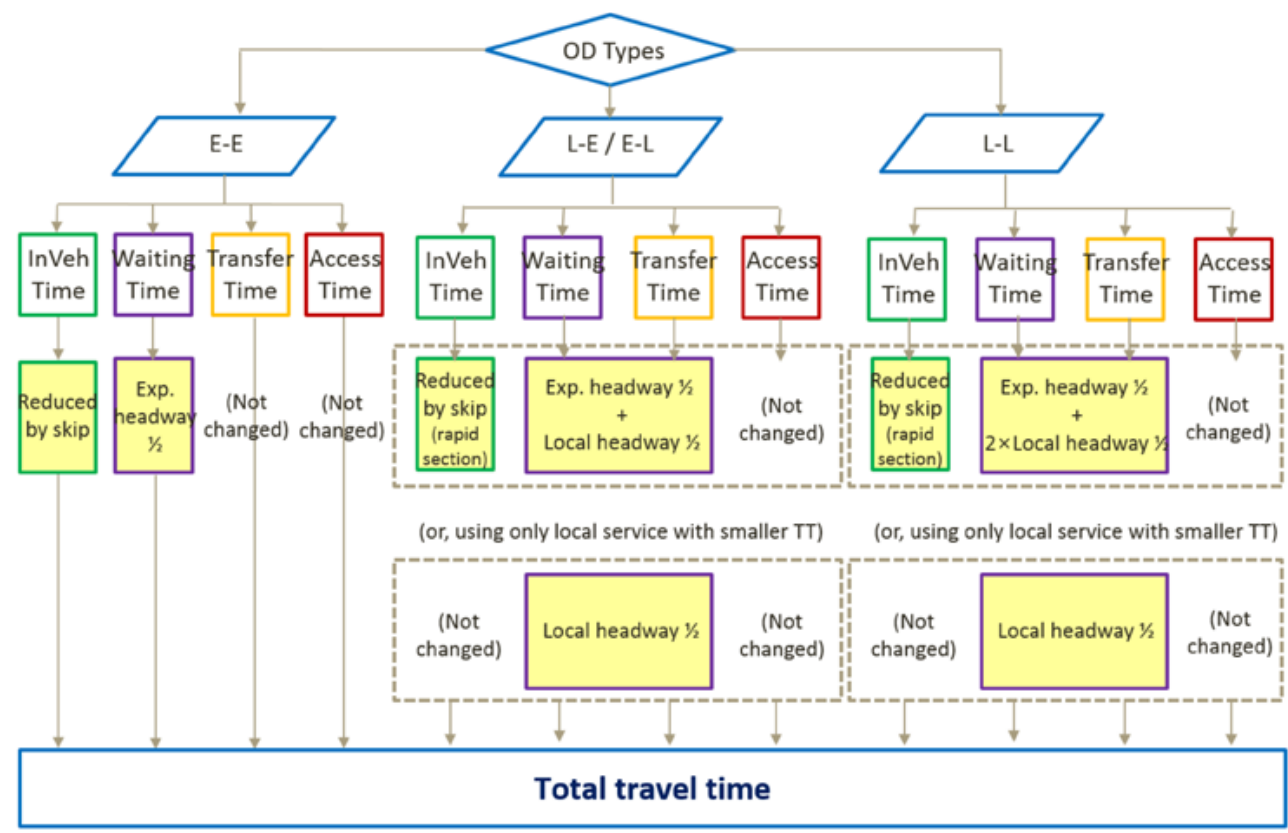




\section{Genetic Algorithm Analysis}

This study used a GA to obtain an optimal solution efficiently that contains an iterative calculation of the limited-bus stops combination and total travel time of passengers. The limited-bus stops were used as chromosomes, and the binary integer matrix were used as a gene (0: limited-bus skips the stop, 1: limited-bus stops at the stop). In every iteration, a gene was evolved until total travel time was tolerantly minimized. For example, optimal limited-bus stops of the certain bus route which has 10 stops were decided as $1^{\text {st }}, 3^{\text {rd }}, 7^{\text {th }}$, and $9^{\text {th }}$ stops, the final gene is expressed as $[1,0,1,0,0,0,1,0,1,0]$. The fitness of each gene was evaluated based on the objective function - the total travel time. Detailed setting values are as follows:

- Population size: 200 (to attain optimal value from enough population)

- Population creation function: Uniform (design variable type is binary)

- Fitness scaling function: Rank (scales the raw scores based on the rank of each individual instead of its score)

- Selection function: Stochastic uniform (lays out a line in which each parent corresponds to a section of the line of length proportional to its scaled value)

- Elite count: $0.05 \times$ (population size) (to prevent losing excellent solution while evolve to next generation)

- Reproduction crossover fraction: 0.8 (80\% of former population is produced by crossover to prevent excessive changing)

- Mutation function: Uniform (rate: 0.01 ) (each gene is given a probability rate and replaced to an initial value when probability is lower than setting rate [0.01])

- Crossover function: Scattered (creates a random binary variable and selects the genes where the vector is 1 from the first parent, and the genes where the vector is 0 from the second parent, and combines the genes to form the child)

- Migration direction: Forward (migration takes place toward the last subpopulation)

- Stopping criteria: Function tolerance $10^{-7}$ (the algorithm stops if the average relative change in the best fitness function value which is less than or equal to $\left.10^{-7}\right)$

\section{Analytical Results}

\section{Scenario-based Analysis}

The results shown in Table 2 are the average values of five repeated analyses by $M A T L A B$. Among the various influencing factors, the OD pattern influenced travel time savings the most. Therefore, the route having certain stops that show highly concentrated boarding or alighting behavior would be chosen for a limited-stop bus 
route. Also, routes that have longer route length, average trip length, or shorter stop spacing have an advantage as a limited-stop bus route. This is because longer route length ensures a greater number of passengers and longer average trip length results in a higher travel time savings rate when using a limited-stop bus. When the original stop spacing is short, a local bus should frequently repeat acceleration and deceleration at each bus stop to board and alight passengers. If a limited-stop bus is introduced, travel time savings effects by skipping several stops are higher than longer stop spacing for certain distances.

TABLE 2.

Travel Time Savings Rate after Limited-stop Bus Introduction, Compared to All Local Services

\begin{tabular}{|c|c|c|c|c|}
\hline \multirow{2}{*}{ Route Length } & $\mathrm{H}(42.4 \mathrm{~km})$ & $\mathrm{M}(32.5 \mathrm{~km})$ & $\mathrm{L}(19.7 \mathrm{~km})$ & Max. / Min. \\
\cline { 2 - 5 } & $5.6 \%$ & $5.4 \%$ & $5.0 \%$ & $112 \%$ \\
\hline \multirow{2}{*}{ Stop Spacing } & $\mathrm{H}(470 \mathrm{~m})$ & $\mathrm{M}(430 \mathrm{~m})$ & $\mathrm{L}(390 \mathrm{~m})$ & Max. / Min \\
\cline { 2 - 5 } & $4.9 \%$ & $5.3 \%$ & $5.9 \%$ & $121 \%$ \\
\hline $\begin{array}{c}\text { Average Trip } \\
\text { Length }\end{array}$ & $\mathrm{H}(4.09 \mathrm{~km})$ & $\mathrm{M}(3.36 \mathrm{~km})$ & $\mathrm{L}(2.84 \mathrm{~km})$ & Max. / Min \\
\cline { 2 - 5 } & $5.7 \%$ & $5.3 \%$ & $5.0 \%$ & $115 \%$ \\
\hline \multirow{2}{*}{ OD Pattern } & $\mathrm{Flat}$ & Two Peaks & Four Peaks & Max. / Min \\
\cline { 2 - 5 } & $4.2 \%$ & $5.8 \%$ & $6.0 \%$ & $142 \%$ \\
\hline
\end{tabular}

$H=$ High, $M=$ Medium, $L=$ Low, Max. $/$ Min. = Maximum value divided by minimum value among high, medium, and low values

Multiple regression analysis between travel time savings rate and each factor was performed as presented in Table 3. The equation of the multiple regression model is as follows:

$$
\text { TTSR }=8.194+0.026 \times \text { ODVar }-0.015 \times S S+0.630 \times A T L
$$

Where:

$$
\begin{aligned}
& \text { TTSR = Travel time savings rate } \\
& \text { ODVar = OD variance } \\
& S S=\text { Stop spacing } \\
& A T L=\text { Average trip length }
\end{aligned}
$$

Adjusted R-squared value (0.864) indicates that the regression line highly fits the data. From the collinearity statistics, VIF values were around 1, which means there is low probability of multicollinearity among the explanatory variables. The OD variance factor (represents OD pattern as a quantified value) shows the highest standardized coefficient value (0.803), which means this factor should be considered first to the LSBRS, and is followed by stop spacing factor $(-0.451)$ and average trip length factor $(0.298)$. OD variance was calculated by the variance between the number of passengers boarding or alighting at each stop of specific routes. When OD variance is high, the stops that have concentrated passenger demand would be chosen as limited stops; therefore limitedstop bus service becomes more efficient with only a few stops. Route length factor was excluded by using a stepwise variable selection method to reduce collinearity. 
TABLE 3.

Multiple Regression Model between Travel Time Savings

Rate and Route Length,

Stop Spacing, Average Trip Length, and OD Variance from

Scenario-based Analysis

\begin{tabular}{|c|c|c|c|c|c|c|c|}
\hline \multirow[t]{2}{*}{ Variables } & \multicolumn{2}{|c|}{$\begin{array}{l}\text { Unstandardized } \\
\text { Coefficients }\end{array}$} & \multirow{2}{*}{$\begin{array}{c}\begin{array}{c}\text { Standardized } \\
\text { Coefficients }\end{array} \\
\text { Beta }\end{array}$} & \multirow[t]{2}{*}{$\mathbf{t}$} & \multirow[t]{2}{*}{ Sig. } & \multicolumn{2}{|c|}{$\begin{array}{c}\text { Collinearity } \\
\text { Statistics }\end{array}$} \\
\hline & B & Std. Error & & & & Tolerance & VIF \\
\hline (Constant) & 8.194 & 0.675 & & 12.132 & .000 & & \\
\hline OD Variance & 0.026 & 0.001 & 0.803 & 19.028 & .000 & 0.992 & 1.008 \\
\hline Stop Spacing & -0.015 & 0.001 & -0.451 & -10.696 & .000 & 0.992 & 1.008 \\
\hline Average Trip Length & 0.630 & 0.089 & 0.298 & 7.081 & .000 & 1.000 & 1.000 \\
\hline R-square & 0.864 & & F-statistic & 106.47 & & & \\
\hline Adjusted R-square & 0.859 & & $p$-value & 0.000 & & & \\
\hline
\end{tabular}

Table 4 shows the travel time savings rate of 81 scenarios; most of the high-ranking scenarios had two or more factors among route length, stop spacing, and average trip length that satisfy each factor at the medium or high level. Therefore, this study defined LSBRS criteria as such that a limited-stop bus route should satisfy two or more of the following medium-level criteria: more than $32.5 \mathrm{~km}$ of one-way route length, less than $430 \mathrm{~m}$ of stop spacing, and more than $3.36 \mathrm{~km}$ of average trip length. Also, OD patterns that have large variances would be suitable for limited-stop bus route.

TABLE 4.

Travel Time Savings Rate of 81 Scenarios (Top 20)

\begin{tabular}{|c|c|c|c|c|c|c|c|}
\hline Rank & $\begin{array}{c}\text { Route } \\
\text { Length }\end{array}$ & $\begin{array}{c}\text { Stop } \\
\text { Spacing }\end{array}$ & $\begin{array}{c}\text { Average } \\
\text { Trip Length }\end{array}$ & $\begin{array}{c}\text { OD } \\
\text { Pattern }\end{array}$ & $\begin{array}{c}\text { Travel Time } \\
\text { Savings Rate } \\
(\%)\end{array}$ & $\begin{array}{c}\text { Total Travel } \\
\text { Time } \\
\text { (before, min.) }\end{array}$ & $\begin{array}{c}\text { Total Travel } \\
\text { Time } \\
\text { (after, } \text { min.) }\end{array}$ \\
\hline 1 & $\mathrm{H}(42.4 \mathrm{~km})$ & $\mathrm{L}(390 \mathrm{~m})$ & $\mathrm{H}(4.09 \mathrm{~km})$ & 4 peaks & 8.14 & 5541.0 & 5089.8 \\
\hline 2 & $\mathrm{~L}(19.7 \mathrm{~km})$ & $\mathrm{L}(390 \mathrm{~m})$ & $\mathrm{H}(4.09 \mathrm{~km})$ & 2 peaks & 7.57 & 2309.5 & 2134.6 \\
\hline 3 & $\mathrm{H}(42.4 \mathrm{~km})$ & $\mathrm{L}(390 \mathrm{~m})$ & $\mathrm{M}(3.36 \mathrm{~km})$ & 2 peaks & 7.34 & 4864.6 & 4507.7 \\
\hline 4 & $\mathrm{M}(32.5 \mathrm{~km})$ & $\mathrm{L}(390 \mathrm{~m})$ & $\mathrm{M}(3.36 \mathrm{~km})$ & 4 peaks & 7.33 & 3651.8 & 3384.1 \\
\hline 5 & $\mathrm{H}(42.4 \mathrm{~km})$ & $\mathrm{M}(430 \mathrm{~m})$ & $\mathrm{H}(4.09 \mathrm{~km})$ & 4 peaks & 7.27 & 5502.8 & 5102.8 \\
\hline 6 & $\mathrm{H}(42.4 \mathrm{~km})$ & $\mathrm{L}(390 \mathrm{~m})$ & $\mathrm{H}(4.09 \mathrm{~km})$ & 2 peaks & 7.11 & 5533.1 & 5140.0 \\
\hline 7 & $\mathrm{M}(32.5 \mathrm{~km})$ & $\mathrm{L}(390 \mathrm{~m})$ & $\mathrm{H}(4.09 \mathrm{~km})$ & 4 peaks & 6.86 & 4051.2 & 3773.5 \\
\hline 8 & $\mathrm{H}(42.4 \mathrm{~km})$ & $\mathrm{H}(470 \mathrm{~m})$ & $\mathrm{H}(4.09 \mathrm{~km})$ & 4 peaks & 6.79 & 5579.2 & 5200.7 \\
\hline 9 & $\mathrm{H}(42.4 \mathrm{~km})$ & $\mathrm{L}(390 \mathrm{~m})$ & $\mathrm{L}(2.84 \mathrm{~km})$ & 2 peaks & 6.71 & 4435.6 & 4137.9 \\
\hline 10 & $\mathrm{~L}(19.7 \mathrm{~km})$ & $\mathrm{M}(430 \mathrm{~m})$ & $\mathrm{H}(4.09 \mathrm{~km})$ & 2 peaks & 6.61 & 2387.0 & 2229.2 \\
\hline 11 & $\mathrm{H}(42.4 \mathrm{~km})$ & $\mathrm{M}(430 \mathrm{~m})$ & $\mathrm{M}(3.36 \mathrm{~km})$ & 2 peaks & 6.58 & 4921.7 & 4598.0 \\
\hline 12 & $\mathrm{M}(32.5 \mathrm{~km})$ & $\mathrm{L}(390 \mathrm{~m})$ & $\mathrm{L}(2.84 \mathrm{~km})$ & 2 peaks & 6.56 & 3406.7 & 3183.3 \\
\hline 13 & $\mathrm{H}(42.4 \mathrm{~km})$ & $\mathrm{L}(390 \mathrm{~m})$ & $\mathrm{M}(3.36 \mathrm{~km})$ & 4 peaks & 6.56 & 4955.3 & 4630.2 \\
\hline 14 & $\mathrm{M}(32.5 \mathrm{~km})$ & $\mathrm{M}(430 \mathrm{~m})$ & $\mathrm{M}(3.36 \mathrm{~km})$ & 4 peaks & 6.54 & 3705.0 & 3462.7 \\
\hline 15 & $\mathrm{~L}(19.7 \mathrm{~km})$ & $\mathrm{L}(390 \mathrm{~m})$ & $\mathrm{M}(3.36 \mathrm{~km})$ & 2 peaks & 6.47 & 2123.2 & 1985.9 \\
\hline 16 & $\mathrm{M}(32.5 \mathrm{~km})$ & $\mathrm{L}(390 \mathrm{~m})$ & $\mathrm{H}(4.09 \mathrm{~km})$ & 2 peaks & 6.44 & 4174.4 & 3905.5 \\
\hline 17 & $\mathrm{H}(42.4 \mathrm{~km})$ & $\mathrm{M}(430 \mathrm{~m})$ & $\mathrm{H}(4.09 \mathrm{~km})$ & 2 peaks & 6.37 & 5647.2 & 5287.5 \\
\hline 18 & $\mathrm{M}(32.5 \mathrm{~km})$ & $\mathrm{L}(390 \mathrm{~m})$ & $\mathrm{L}(2.84 \mathrm{~km})$ & 4 peaks & 6.25 & 3337.8 & 3129.1 \\
\hline 19 & $\mathrm{~L}(19.7 \mathrm{~km})$ & $\mathrm{M}(430 \mathrm{~m})$ & $\mathrm{M}(3.36 \mathrm{~km})$ & 2 peaks & 6.19 & 2145.5 & 2012.8 \\
\hline 20 & $\mathrm{M}(32.5 \mathrm{~km})$ & $\mathrm{H}(470 \mathrm{~m})$ & $\mathrm{M}(3.36 \mathrm{~km})$ & 4 peaks & 6.10 & 3713.8 & 3487.4 \\
\hline
\end{tabular}




\section{Case Study Analysis}

As a result of applying the model to 73 regular bus routes that operate in Suwon, travel time savings rate placed between $9.0 \%$ and $19.0 \%$, which is larger than one of the scenario-based analysis. This is because the variation of actual OD is larger than that of scenario OD, which means passenger coverage is widened under the same number of limited-stops.

LSBRS criteria and the LSBRS regression model, which are proposed in the scenariobased analysis, are applied to the routes of case study. As presented in Table 5, most of the selected routes by LSBRS criteria are located in the upper rank along with higher values of travel time savings, according to the case-study analysis. Also, the travel time savings rank proposed by the LSBRS regression model shows a similar tendency with that of the case-study analysis, supported by Wilcoxon signed ranks test in Table 6, meaning that the assumption of difference between two pairs of the LSBRS regression model and the case-study analysis results are rejected (Asymp. Sig. [2-tailed] $=0.952>$ 0.05).

TABLE 5. Travel Time Savings Rate of Case Study Routes Compared to LSBRS Criteria and LSBRS Regression Model

\begin{tabular}{|c|c|c|c|c|c|c|c|c|c|}
\hline \multirow{2}{*}{ Rank } & \multirow{2}{*}{$\begin{array}{l}\text { Route } \\
\text { No. }\end{array}$} & \multirow{2}{*}{$\begin{array}{l}\text { Route Length } \\
\text { (roundtrip, km) }\end{array}$} & \multirow{2}{*}{$\begin{array}{l}\text { Average Trip } \\
\text { Length }(\mathbf{k m})\end{array}$} & \multirow{2}{*}{$\begin{array}{c}\text { Average } \\
\text { Stop Spacing } \\
\text { (m) }\end{array}$} & \multirow{2}{*}{$\begin{array}{c}\text { OD } \\
\text { Variance }\end{array}$} & \multirow{2}{*}{$\begin{array}{c}\text { Travel Time } \\
\text { Savings (TTS) } \\
\text { Rate (\%) }\end{array}$} & \multirow{2}{*}{$\begin{array}{c}\text { Satisfying } \\
\text { LSBRS } \\
\text { Criteria }\end{array}$} & \multicolumn{2}{|c|}{$\begin{array}{c}\text { LSBRS Regression } \\
\text { Model }\end{array}$} \\
\hline & & & & & & & & TTS Rate (\%) & Rank \\
\hline 1 & $10-2$ & 20.0 & 4.28 & 345 & 152 & 19.0 & $x$ & 9.7 & 21 \\
\hline 2 & 400 & 97.0 & 8.20 & 519 & 313 & 17.5 & $\mathrm{O}$ & 13.7 & 3 \\
\hline 3 & 10 & 85.0 & 8.54 & 503 & 222 & 17.2 & $\mathrm{O}$ & 11.8 & 7 \\
\hline 4 & 61 & 62.6 & 3.61 & 396 & 132 & 16.7 & $x$ & 7.9 & 43 \\
\hline 5 & 660 & 76.4 & 8.35 & 527 & 236 & 16.2 & $\mathrm{O}$ & 11.7 & 9 \\
\hline 6 & 990 & 82.4 & 7.15 & 535 & 319 & 16.2 & $\mathrm{O}$ & 13.0 & 5 \\
\hline 7 & $34-1$ & 50.6 & 5.38 & 444 & 148 & 16.1 & $x$ & 8.8 & 31 \\
\hline 8 & 60 & 93.3 & 6.14 & 438 & 165 & 16.0 & $x$ & 9.8 & 19 \\
\hline 9 & $10-5$ & 47.0 & 6.07 & 435 & 181 & 15.9 & $\mathrm{x}$ & 10.2 & 14 \\
\hline 10 & $700-2$ & 57.2 & 6.42 & 427 & 207 & 15.9 & $\mathrm{O}$ & 11.2 & 10 \\
\hline 11 & 66 & 65.0 & 6.86 & 428 & 138 & 15.8 & $x$ & 9.7 & 20 \\
\hline 12 & $400-4$ & 68.5 & 6.57 & 493 & 290 & 15.8 & $\mathrm{O}$ & 12.5 & 6 \\
\hline 13 & 35 & 53.1 & 8.61 & 482 & 185 & 15.7 & $x$ & 11.2 & 11 \\
\hline 14 & 4-1 & 37.4 & 4.18 & 411 & 110 & 15.6 & $x$ & 7.5 & 55 \\
\hline 15 & 38 & 41.7 & 9.77 & 522 & 284 & 15.6 & $x$ & 13.9 & 2 \\
\hline 16 & $13-4$ & 45.8 & 4.80 & 463 & 457 & 15.6 & $x$ & 16.2 & 1 \\
\hline 17 & 34 & 60.5 & 5.13 & 451 & 149 & 15.3 & $x$ & 8.5 & 36 \\
\hline 18 & 900 & 83.4 & 12.77 & 502 & 177 & 14.9 & $\mathrm{O}$ & 13.3 & 4 \\
\hline 19 & 7 & 63.4 & 4.29 & 425 & 232 & 14.8 & $\mathrm{O}$ & 10.5 & 12 \\
\hline 20 & 20 & 57.7 & 5.68 & 473 & 161 & 14.8 & $x$ & 8.9 & 29 \\
\hline 21 & $7-2$ & 66.2 & 4.65 & 409 & 194 & 14.7 & $\mathrm{O}$ & 10.0 & 17 \\
\hline
\end{tabular}


TABLE 5 (cont'd). Travel Time Savings Rate of Case Study Routes Compared to LSBRS Criteria and LSBRS Regression Model

\begin{tabular}{|c|c|c|c|c|c|c|c|c|c|}
\hline \multirow{2}{*}{ Rank } & \multirow{2}{*}{$\begin{array}{l}\text { Route } \\
\text { No. }\end{array}$} & \multirow{2}{*}{$\begin{array}{l}\text { Route Length } \\
\text { (roundtrip, km) }\end{array}$} & \multirow{2}{*}{$\begin{array}{l}\text { Average Trip } \\
\text { Length }(\mathbf{k m})\end{array}$} & \multirow{2}{*}{$\begin{array}{c}\text { Average } \\
\text { Stop Spacing } \\
(\mathrm{m})\end{array}$} & \multirow{2}{*}{$\begin{array}{c}\text { OD } \\
\text { Variance }\end{array}$} & \multirow{2}{*}{$\begin{array}{l}\text { Travel Time } \\
\text { Savings (TTS) } \\
\text { Rate (\%) }\end{array}$} & \multirow{2}{*}{$\begin{array}{l}\text { Satisfying } \\
\text { LSBRS } \\
\text { Criteria }\end{array}$} & \multicolumn{2}{|c|}{$\begin{array}{c}\text { LSBRS Regression } \\
\text { Model }\end{array}$} \\
\hline & & & & & & & & TTS Rate (\%) & Rank \\
\hline 22 & $2-2$ & 41.6 & 3.07 & 408 & 134 & 14.7 & $x$ & 7.5 & 57 \\
\hline 23 & $66-4$ & 76.0 & 5.49 & 404 & 121 & 14.4 & $x$ & 8.7 & 32 \\
\hline 24 & 310 & 36.9 & 4.15 & 415 & 189 & 14.1 & $\mathrm{O}$ & 9.5 & 23 \\
\hline 25 & $720-3$ & 53.6 & 3.70 & 436 & 145 & 14.1 & $x$ & 7.8 & 45 \\
\hline 26 & 730 & 70.2 & 4.44 & 444 & 184 & 13.9 & $\mathrm{O}$ & 9.1 & 27 \\
\hline 27 & 46 & 42.5 & 4.22 & 448 & 171 & 13.8 & $x$ & 8.6 & 35 \\
\hline 28 & 27 & 52.1 & 4.64 & 401 & 117 & 13.8 & $x$ & 8.1 & 39 \\
\hline 29 & $7-1$ & 38.7 & 4.68 & 387 & 161 & 13.5 & $x$ & 9.5 & 22 \\
\hline 30 & $720-2$ & 81.4 & 4.44 & 419 & 176 & 13.5 & $\mathrm{O}$ & 9.3 & 24 \\
\hline 31 & 13-1 & 48.7 & 3.11 & 380 & 150 & 13.4 & $x$ & 8.3 & 38 \\
\hline 32 & 5 & 45.7 & 4.41 & 423 & 209 & 13.3 & $\mathrm{O}$ & 10.1 & 16 \\
\hline 33 & 30 & 35.3 & 5.00 & 484 & 220 & 13.1 & $x$ & 9.8 & 18 \\
\hline 34 & 300 & 73.6 & 9.66 & 522 & 202 & 13.1 & $\mathrm{O}$ & 11.7 & 8 \\
\hline 35 & 63 & 50.3 & 4.22 & 405 & 100 & 13.0 & $x$ & 7.4 & 59 \\
\hline 36 & $11-1$ & 49.6 & 4.26 & 459 & 199 & 12.9 & $x$ & 9.2 & 26 \\
\hline 37 & 99 & 80.5 & 3.57 & 426 & 126 & 12.9 & $x$ & 7.3 & 61 \\
\hline 38 & 777 & 55.8 & 6.29 & 537 & 241 & 12.8 & $x$ & 10.4 & 13 \\
\hline 39 & 202 & 46.3 & 4.18 & 482 & 131 & 12.7 & $x$ & 7.0 & 70 \\
\hline 40 & $13-5$ & 50.3 & 4.63 & 479 & 175 & 12.7 & $x$ & 8.5 & 37 \\
\hline 41 & $20-1$ & 47.1 & 4.80 & 486 & 138 & 12.6 & $x$ & 7.5 & 56 \\
\hline 42 & 25 & 45.5 & 5.41 & 489 & 134 & 12.5 & $x$ & 7.7 & 46 \\
\hline 43 & $720-1$ & 91.5 & 4.53 & 428 & 112 & 12.5 & $x$ & 7.5 & 54 \\
\hline 44 & 3 & 38.5 & 3.77 & 374 & 87 & 12.5 & $x$ & 7.2 & 65 \\
\hline 45 & 301 & 76.2 & 5.54 & 476 & 166 & 12.5 & $x$ & 8.8 & 30 \\
\hline 46 & 62 & 34.8 & 3.61 & 430 & 124 & 12.4 & $x$ & 7.2 & 64 \\
\hline 47 & $9-1$ & 52.5 & 4.21 & 520 & 214 & 12.4 & $x$ & 8.6 & 34 \\
\hline 48 & $62-1$ & 62.6 & 4.17 & 396 & 107 & 12.3 & $x$ & 7.7 & 49 \\
\hline 49 & 37 & 46.2 & 3.77 & 399 & 135 & 12.3 & $x$ & 8.1 & 40 \\
\hline 50 & $99-2$ & 51.1 & 3.66 & 433 & 119 & 12.2 & $x$ & 7.1 & 68 \\
\hline 51 & $5-1$ & 44.6 & 4.08 & 479 & 163 & 12.2 & $x$ & 7.8 & 44 \\
\hline 52 & 65 & 51.7 & 4.48 & 438 & 121 & 12.2 & $x$ & 7.6 & 53 \\
\hline 53 & $82-2$ & 36.0 & 3.31 & 409 & 133 & 12.1 & $x$ & 7.6 & 52 \\
\hline 54 & $9-2$ & 39.9 & 4.36 & 464 & 236 & 12.0 & $x$ & 10.1 & 15 \\
\hline 55 & 88 & 42.5 & 3.22 & 401 & 134 & 11.9 & $x$ & 7.7 & 48 \\
\hline 56 & $2-1$ & 38.9 & 3.10 & 377 & 159 & 11.7 & $x$ & 8.6 & 33 \\
\hline 57 & $88-1$ & 40.4 & 3.18 & 429 & 149 & 11.6 & $x$ & 7.6 & 50 \\
\hline 58 & 64 & 70.1 & 4.11 & 438 & 124 & 11.6 & $x$ & 7.4 & 58 \\
\hline
\end{tabular}


TABLE 5 (cont'd). Travel Time Savings Rate of Case Study Routes Compared to LSBRS Criteria and LSBRS Regression Model

\begin{tabular}{|c|c|c|c|c|c|c|c|c|c|}
\hline \multirow{2}{*}{ Rank } & \multirow{2}{*}{$\begin{array}{l}\text { Route } \\
\text { No. }\end{array}$} & \multirow{2}{*}{$\begin{array}{l}\text { Route Length } \\
\text { (roundtrip, km) }\end{array}$} & \multirow{2}{*}{$\begin{array}{l}\text { Average Trip } \\
\text { Length }(\mathbf{k m})\end{array}$} & \multirow{2}{*}{$\begin{array}{c}\text { Average } \\
\text { Stop Spacing } \\
\text { (m) }\end{array}$} & \multirow{2}{*}{$\begin{array}{c}\text { OD } \\
\text { Variance }\end{array}$} & \multirow{2}{*}{$\begin{array}{c}\text { Travel Time } \\
\text { Savings (TTS) } \\
\text { Rate (\%) }\end{array}$} & \multirow{2}{*}{$\begin{array}{l}\text { Satisfying } \\
\text { LSBRS } \\
\text { Criteria }\end{array}$} & \multicolumn{2}{|c|}{$\begin{array}{c}\text { LSBRS Regression } \\
\text { Model }\end{array}$} \\
\hline & & & & & & & & TTS Rate (\%) & Rank \\
\hline 59 & 51 & 34.4 & 3.67 & 453 & 140 & 11.5 & $x$ & 7.4 & 60 \\
\hline 60 & $15-1$ & 58.8 & 3.78 & 474 & 209 & 11.2 & $x$ & 8.9 & 28 \\
\hline 61 & 85 & 29.0 & 3.27 & 414 & 116 & 11.1 & $x$ & 7.1 & 69 \\
\hline 62 & 80 & 33.5 & 3.18 & 419 & 97 & 11.0 & $x$ & 6.4 & 73 \\
\hline 63 & 36 & 53.0 & 3.33 & 449 & 144 & 10.9 & $x$ & 7.3 & 62 \\
\hline 64 & $83-1$ & 22.3 & 2.84 & 371 & 87 & 10.7 & $x$ & 6.7 & 71 \\
\hline 65 & $82-1$ & 33.8 & 2.78 & 402 & 146 & 10.5 & $x$ & 7.7 & 47 \\
\hline 66 & 11 & 70.4 & 4.22 & 499 & 182 & 9.9 & $\mathrm{O}$ & 8.1 & 41 \\
\hline 67 & 9 & 35.4 & 3.57 & 437 & 156 & 9.9 & $x$ & 7.9 & 42 \\
\hline 68 & 98 & 49.7 & 3.42 & 401 & 107 & 9.7 & $x$ & 7.1 & 66 \\
\hline 69 & 13 & 33.9 & 3.97 & 458 & 207 & 9.7 & $x$ & 9.2 & 25 \\
\hline 70 & $92-1$ & 49.4 & 3.60 & 437 & 142 & 9.5 & $x$ & 7.6 & 51 \\
\hline 71 & 39 & 33.3 & 2.39 & 411 & 143 & 9.4 & $x$ & 7.2 & 63 \\
\hline 72 & 92 & 36.8 & 2.78 & 405 & 125 & 9.4 & $x$ & 7.1 & 67 \\
\hline 73 & 112 & 31.5 & 3.22 & 426 & 103 & 9.0 & $x$ & 6.5 & 72 \\
\hline
\end{tabular}

Therefore, the criteria proposed in this study could be applied without a complicated analysis to cities that are considering implementing a limited-stop bus service. However, some routes such as $1^{\text {st }}$ rank or $4^{\text {th }}$ rank in Table 5 show big differences between the results of case-study analysis and the results of LSBRS suggestion. This is because of a gap between the scenarios and the actual routes, such as (a) the stop spacing distance of actual routes has a wide range of values while that of the scenario routes have identical values, or (b) the complexity of the OD pattern of actual routes is much higher than that of the scenario routes.
TABLE 6.

Wilcoxon Signed Ranks Test for Travel Times Saved Rank between (a) Case Study and (b) LSBRS Regression Model

\begin{tabular}{|l|l|c|c|c|}
\hline & & N & Mean Rank & Sum of Ranks \\
\hline \multirow{5}{*}{ (b) - (a) } & Negative Ranks & 37 & 34.82 & 1288.50 \\
\hline & Positive Ranks & 34 & 37.28 & 1267.50 \\
\hline & Ties & 2 & & \\
\hline & Total & 73 & & \\
\hline & Z & -0.060 & & \\
\hline & Asymp. Sig. (2-tailed) & 0.952 & & \\
\hline
\end{tabular}

\section{Conclusions}

The bus system is one of the most easily accessible systems among the various transit modes because of its short distances between stops. However, this attribute causes slow operation speeds and weakens its competitiveness when compared to other 
transportation modes. In recent years, express bus service has come into the spotlight by overcoming its limitations to travel time while maintaining its accessibility when it operates with local bus services. To achieve an efficient bus system, a systematic approach to determine the optimal routes and stops for the express services is necessary. This study used smart card data and a genetic algorithm to develop the LSBRS criteria and the regression model. More specifically, the total travel time savings rates were calculated for various scenarios with their influencing factors to set the LSBRS criteria and regression model, and then these methods were applied to the case of Suwon, Korea.

Among the factors that influence the effectiveness of limited-stop bus implementation, concentrated OD pattern (represented by OD variance) influences travel time savings the most. Also, shorter stop spacing and longer average trip length have an advantage in maximizing the effectiveness of limited-stop bus implementation. In terms of the details of the criteria, limited-stop bus routes should have a large OD variance and satisfy two or more of the following medium-level criteria: more than $32.5 \mathrm{~km}$ of one-way route length, less than $430 \mathrm{~m}$ of stop spacing and more than $3.36 \mathrm{~km}$ of average trip length. In reference to the coefficient values of the regression model, the OD variance factor should be considered first to the LSBRS criteria, followed by stop spacing factor and average trip length factor.

Comparing the rankings of the travel time savings proposed by the LSBRS regression model and the case study of Suwon, the pairs of two ranks show a similar tendency supported by the Wilcoxon signed ranks test. Therefore, the method proposed in this study could be applied to cities that are considering the implementation of a limitedstop bus service.

A limited-stop bus is one of the alternatives that satisfies both accessibility and mobility without great financial investment. Further studies focused on finding the adequate range of the number of limited-stop bus routes or enhancing the accuracy of LSBRS model are required.

\section{Acknowledgment}

This research was supported by a National Research Foundation of Korea (NRF) grant funded by the Korean government (MSIP) (NRF-2010-0028693) and the National Transportation Center (NTC) at Morgan State University.

\section{References}

Agard, B., C. Morency, and M. Trépanier. 2006. “Mining Public Transport User Behaviour from Smart Card Data." Presented at 12th IFAC Symposium on Information Control Problems in Manufacturing-INCOM: 17-19.

Amiripour, S. M., A. S. Mohaymany, and A. A. Ceder. 2015. "Optimal Modification of Urban Bus Network Routes Using a Genetic Algorithm." Journal of Transportation Engineering, 141(3): 04014081. 
Cevallos, F., and F. Zhao. 2006. "Minimizing Transfer Times in Public Transit Network with Genetic Algorithm." Transportation Research Record, 1971: 74-79.

City of Seoul. 2014. 54th 2014 Seoul Statistical Year Book (as of 2013).

Fan, W., and R. B. Machemehl. 2004. "Optimal Transit Route Network Design Problem: Algorithms, Implementations, and Numerical Results." Technical Report, SWUTC/04/167244-1.

Fan, W., and R. B. Machemehl. 2006. "Optimal Transit Route Network Design Problem with Variable Transit Demand: Genetic Algorithm Approach." Journal of Transportation Engineering, 132(1): 40-51.

Fan, W., and R. B. Machemehl. 2009. "Do Transit Users Just Wait for Buses or Wait with Strategies? Some Numerical Results that Transit Planners Should See." Transportation Research Record, 2111: 169-176.

Jánošíková, L'., J. Slavík, and M. Koháni. 2014. “Estimation of A Route Choice Model for Urban Public Transport Using Smart Card Data." Transportation Planning and Technology, 37(7): 638-648.

Jun, C., and Y. Dongyuan. 2013. "Estimating Smart Card Commuters Origin-Destination Distribution Based on APTS Data." Journal of Transportation Systems Engineering and Information Technology, 13(4): 47-53.

Kalantari, N., M. H. Zamanian, and S. M. M. Amiripour. 2014. "Bus Network Modification Problem: A New Approach to Bus Network Design." 93rd Annual Meeting of the Transportation Research Board, Washington, DC, Paper No. 14-4310.

Kuan, S. N., H. L. Ong, and K. M. Ng. 2006. "Solving the Feeder Bus Network Design Problem by Genetic Algorithms and Ant Colony Optimization." Advances in Engineering Software, 37(6): 351-359.

Kurauchi, F., J. D. Schmöcker, H. Shimamoto, and S. M. Hassan. 2014. "Variability of Commuters' Bus Line Choice: An Analysis of Oyster Card Data." Public Transport, 6(1-2): 21-34.

Lee, Y.-J., Shariat, S. and K. Choi. 2014. "Optimizing Skip-Stop Rail Transit Stopping Strategy using a Genetic Algorithm." Journal of Public Transportation, 17(2): 163-192.

Leiva, C., J. C. Muñoz, R. Giesen, and H. Larrain. 2010. “Design of Limited-Stop Services for an Urban Bus Corridor with Capacity Constraints." Transportation Research Part B: Methodological, 44(10): 1186-1201.

Metropolitan Transit Authority (of Korea). 2013. 2011 Seoul Metropolitan Area Traffic Analysis Base Data.

Morency, C., M. Trepanier, and B. Agard. 2007. "Measuring Transit Use Variability with Smart-Card Data." Transport Policy, 14: 193-203.

Nassir, N., A. Khani, S. Lee, H. Noh, and M. Hickman. 2011. "Transit Stop-Level OriginDestination Estimation through Use of Transit Schedule and Automated Data Collection System." Transportation Research Record, 2263: 140-150. 
Nayeem, M. A., M. K. Rahman, and M. S. Rahman. 2014. "Transit Network Design by Genetic Algorithm with Elitism." Transportation Research Part C: Emerging Technologies, 46: 30-45.

Ngamchai, S. and D. J. Lovell. 2003. "Optimal Time Transfer in Bus Transit Route Network Design Using a Genetic Algorithm." Journal of Transportation Engineering, 129(5): 510-521.

Nishiuchi, H., J. King, and T. Todoroki. 2013. "Spatial-Temporal Daily Frequent Trip Pattern of Public Transport Passengers Using Smart Card Data." International Journal of Intelligent Transportation Systems Research, 11(1): 1-10.

Schwarcz, S. 2004. "Service Design for Heavy Demand Corridors: Limited-Stop Bus Service." Doctoral dissertation, Massachusetts Institute of Technology, Cambridge, MA.

Son, S., K. Choi, and J. Yu. 2007. "An Estimation of Generalized Cost for Transit Assignment." Journal of Korean Society of Transportation, 25(2): 121-132. (In Korean)

Tao, S., J. Corcoran, I. Mateo-Babiano, and D. Rohde. 2014. “Exploring Bus Rapid Transit Passenger Travel Behaviour Using Big Data." Applied Geography, 53: 90-104.

Tétreault, P. R. and A. M. El-Geneidy. 2010. "Estimating Bus Run Times for New LimitedStop Service Using Archived AVL and APC Data." Transportation Research Part A: Policy and Practice, 44(6): 390-402.

Robinson, S. 2013. "Measuring Bus Stop Dwell Time and Time Lost Serving Stop with London iBus Automatic Vehicle Location Data." Transportation Research Record, 2352: 68-75.

Ryus, P., A. Danaher, M. Walker, F. Nichols, W. Carter, E. Ellis, L. Cherrington, and A. Bruzzone. 2013. TCRP Report 165: Transit Capacity and Quality of Service Manual. Transportation Research Board, Washington, DC, Rep. TCRP Report, No. 165, Chapter 3.

Vuchic, V. 2007. Urban Transit: Systems and Technology, Chapter 5. Wiley.

Wang, W. 2010. "Bus Passenger Origin-Destination Estimation and Travel Behavior Using Automated Data Collection Systems in London, UK." Doctoral dissertation, Massachusetts Institute of Technology, Cambridge, MA.

Zargari, S. A., H. Khaksar, and N. Kalantari. 2013. "Bus Network Design by Considering the Location of Depots: A Case Study of Mashhad." 92nd Annual Meeting of the Transportation Research Board, Washington, DC, Paper No. 13-0929.

\section{About the Authors}

YongJU Yı, PH.D. (srzr2001@ajou.ac.kr) received his B.S., M.S., and Ph.D. degrees in transportation systems engineering from Ajou University, South Korea, in 2009, 2011, and 2016, respectively. He is currently a Research Professor in the National Engineering Research Center (ERC) of Sustainable Transportation at Ajou University. His doctoral 
work focuses on the optimization of express bus routes and operation schemes. His research interests also include transportation demand forecasting, traffic signs, and transit-oriented development.

KeECHOo ChOI, PH.D. (keechoo@ajou.ac.kr) is a Professor of Transportation and a Director for the National Engineering Research Center (ERC) of Sustainable Transportation at Ajou University. He studied Civil Engineering at Seoul National University, where he earned his B.S. and M.S., and he earned a Ph.D. from the University of Illinois in 1992. His specialties include travel demand forecasting, ATIS type ITS, sustainable transportation with environmental concerns, and public transportation. He is the founding and managing editor of the International Journal of Sustainable Transportation, an editorial board member of the Journal of ITS, and an editorial board member of Transportmetrica Part B. As a Director of the National TOD-based Sustainable Urban Transportation Center, funded by the Korean government, his current research also covers efficient transfer systems of transportation. He represents the Korean technical committee 2.2 in PIARC, World Road Association, covering improvement of urban mobility.

Young-JAe Lee, Ph.D. (YoungJae.Lee@morgan.edu) is an Associate Professor in the Department of Transportation and Urban Infrastructure Studies at Morgan State University in Baltimore, Maryland. He received his B.S. and M.S. at Seoul National University and another M.S. and Ph.D. at the University of Pennsylvania, conducting research for optimizing a transit network design problem. His main research focus has been the improvement of transit systems, and he has conducted different types of research projects and published papers on improving public transportation systems, including network design, operational efficiency, and ITS application for public transportation. Currently, he is a committee member of the TRB Automated Transit Systems (AP040), an associate editor of the Korea Society of Civil Engineering (KSCE) Journal of Civil Engineering, and an associate editor of Urban Rail Transit. 